complex issue of viability, which is determined by a combination of clinical features of which condition at birth is only one.

We thank all of the medical, nursing, and clerical staff of the 17 perinatal units in the Trent region for their help. This work was funded by Trent Regional Health Authority. ACF is funded by the Spastics Society.
1 Brindle D. MPs call for action to cut baby deaths: targets urged for health regions to improve services. Guardian 1988 Dec 14:2 ( $\mathrm{col} 5$ ).

2 Keirse MJMC. Perinatal mortality rates do not contain what they purport to contain. Lancet 1984; i:1166-9.

3 Field DJ, Smith H, Mason E, Milner AD. Is perinatal mortality still a good indicator of perinatal care? Paediatric and Perinatal Epidemiology 1988;2:2139.

4 World Health Organisation. International classification of diseases, injuries and causes of death. 9th Revision, 1975. Geneva: WHO, 1977:765-6.

(Accepted 11 December 1989)

\title{
Prolonged endometrial stimulation associated with oestradiol implants
}

\author{
Kevin F Gangar, David Fraser, Malcolm I Whitehead, Michael P Cust
}

\begin{abstract}
Objective-To provide information on endometrial stimulation after discontinuation of treatment with oestradiol implants.

Design-Long term follow up of withdrawal bleeding patterns in women taking progestogens cyclically every month after oestradiol implant treatment was ended.

Setting-Specialist menopause clinic.

Subjects - 10 Postmenopausal patients (at least 12 months' amenorrhoea after the last spontaneous period) who were treated with oestradiol implants for typical symptoms of oestrogen deficiency. The oestradiol dose was $50 \mathrm{mg}$, reimplantation occurring roughly every six months. Patients subsequently either needed to discontinue the hormone treatment for medical reasons or expressed a desire to stop treatment.
\end{abstract}

Main outcome measure-Duration of endometrial stimulation-defined as the presence of withdrawal bleeding in response to progestogen given cyclically - after insertion of the last oestradiol implant.

Results-Four patients eventually stopped bleeding, their mean duration of bleeding being 35 months (range 27-43 months). One patient required hysterectomy 26 months after the last implantation because of persistent irregular bleeding despite treatment with high doses of progestogen. Three patients bled for 22,30 , and 36 months and then restarted oestrogen treatment because symptoms returned. The last two patients subsequently continued to bleed 12 and 21 months after the last implantation.

Conclusions - The duration of endometrial stimulation after implantation can be prolonged, up to 43 months. Insertion of oestradiol implants can carry a long term commitment to the cyclical administration of progestogen and regular withdrawal bleeding if endometrial hyperplasia and carcinoma are to be avoided.

College School of Medicine and Dentistry, London SE5 8RX, and Menopause Clinic, Chelsea Hospital for Women, London SW3 Kevin F Gangar, MRCOG, research fellow

David Fraser, $\mathrm{MB}$, research fellow

Malcolm I Whitehead,

FRCOG, senior lecturer and consultant

Michael P Cust, MRCOG, research fellow

Correspondence to: Mr Gangar. prevent endometrial neoplasia. ${ }^{3}$ Progestogenic effects such as physical and psychological symptoms ${ }^{4}$ and the re-establishment of vaginal bleeding are, however, disliked by some women and may reduce compliance.

The information provided in the Data Sheet Compendium and the British National Formulary on the duration of oestradiol implants is inconsistent. The compendium states that the "frequency of replacement [of implants] depends on the duration of activity of the implants administered and the severity of the symptoms. Patients require a further implant when symptoms return, usually every 4 to 8 months." "The British National Formulary states that the duration of 25,50 , and $100 \mathrm{mg}$ oestradiol implants is 36,44 , and 57 weeks, respectively. ${ }^{6}$ The manufacturers in the United Kingdom were unable to provide us with information on how the recommendations in the British National Formulary had been derived (Akzo, personal communication). Furthermore, the meaning of duration is ambiguous. It is not clear whether this term applies only to the relief of symptoms or to stimulation of vulnerable end organs such as the endometrium as well.

To provide information on the stimulatory effects of oestradiol implants on the endometrium we followed up a series of postmenopausal women for between one and three and a half years after they were given their last implant. We considered that endometrial stimulation was occurring if the cyclic addition of a progestogen every month induced a regular withdrawal bleed.

\section{Patients and methods}

All 10 patients had initially presented with at least 12 months' amenorrhoea and had complained of flushes, sweats, and vaginal dryness. One patient (case 7) had undergone bilateral oophorectomy for endometriosis. All received oestradiol $50 \mathrm{mg}$ (Akzo, Oss, The Netherlands), reimplantation occurring roughly every six months, and a progestogen was added for 10-12 days each calendar month. Eventually, further implantation was not performed for the reasons stated in the table, but patients continued to attend the clinic regularly. After the final implantation progestogens were continued for 10-12 days each month, and all patients experienced bleeding after withdrawal of progestogen. No other oestrogens were given during this time, which was verified from the records of the family doctors. We have called the time after the last implantation when cyclic bleeding occurred in relation to progestogen treatment the observation period. At least four venous blood samples were collected from three patients during the observation period for measurement of plasma oestradiol concentrations in either the endocrine unit at the Chelsea Hospital for Women or the department of reproductive medicine at King's College Hospital.

\section{Results}

The mean age before treatment with oestradiol implants was $51 \cdot 2$ years (range 35 to 62 ). The mean age at the end of the observation period was 56.0 (range 42 to 68 ). The table shows the time between the first and 


\begin{tabular}{|c|c|c|c|c|c|c|}
\hline Case No & $\begin{array}{c}\text { Total } \\
\text { oestradiol } \\
\text { dose } \\
(\mathrm{mg})\end{array}$ & $\begin{array}{l}\text { Time between first } \\
\text { and last implants }\end{array}$ & $\begin{array}{c}\text { Average } \\
\text { oestradiol } \\
\text { dose } \\
\text { (mg/year) }\end{array}$ & Reason for discontinuing implant treatment & $\begin{array}{c}\text { Duration of } \\
\text { withdrawal } \\
\text { bleeding } \\
\text { (months) until } \\
\text { final event }\end{array}$ & $\begin{array}{c}\text { Age at end of } \\
\text { observation } \\
\text { period (years) }\end{array}$ \\
\hline 1 & 350 & 3 years 2 months & 96 & Progestogen intolerance & $43^{\star}$ & 57 \\
\hline 2 & 150 & 1 year 3 months & 86 & No symptoms & $40^{\star}$ & 60 \\
\hline 3 & 150 & 1 year 1 month & 95 & No symptoms & $30^{\star}$ & 52 \\
\hline 4 & 225 & 3 years & 64 & Breast carcinoma & $27^{\star}$ & 59 \\
\hline 5 & 225 & 2 years 3 months & 82 & Breakthrough bleeding with atypical hyperplasia & $26+$ & 60 \\
\hline 6 & 375 & 3 years & 107 & No symptoms & $36 \ddagger$ & 54 \\
\hline 7 & 325 & 4 years 6 months & 65 & No symptoms & $30 \neq$ & 42 \\
\hline 8 & 100 & 6 months & 100 & No symptoms & $22 \ddagger$ & 49 \\
\hline 9 & 325 & 3 years 6 months & 81 & No symptoms but atypical hyperplasia & 215 & 68 \\
\hline 10 & 150 & 2 years 2 months & 56 & Worry about breast cancer & $12 \S$ & 59 \\
\hline
\end{tabular}

*Ceased bleeding spontaneously.

last implantations and the total dose of oestradiol given. We calculated the average oestradiol dose a year by assuming that the last implant relieved symptoms for six months and added it to the duration of treatment. The mean average oestradiol dose a year was $83 \mathrm{mg}$.

Further implantation was not performed for various reasons. The commonest was a lack of distressing menopausal symptoms (cases 2, 3, 6, 7, 8, and 9). One patient (case 4) developed breast carcinoma and another (case 10) was concerned about breast cancer because a close relative had recently developed the disease. One patient (case 1) developed noticeable symptoms of progestogen intolerance. Another (case 5) experienced regular monthly withdrawal bleeding in response to progestogen withdrawal but, in addition, had breakthrough bleeding unrelated to the addition of progestogen. Endometrial biopsy showed hyperplasia, and total abdominal hysterectomy and bilateral salpingo-oophorectomy was undertaken. The last patient (case 9) wished to discontinue treatment because she was free of symptoms, but she was found to have atypical hyperplasia on endometrial biopsy. This hyperplasia was successfully reversed by increasing the dose of progestogen.

The duration of regular withdrawal bleeding which followed the last implantation ranged from 12 to 43 months (mean 28.7 months). Four patients (cases 1-4) eventually stopped bleeding spontaneously (they had three months of amenorrhoea despite monthly progestogen addition); their duration of bleeding ranged from 27 to 43 months (mean 35 months). One patient (case 5) bled until she had a hysterectomy 26 months after the last implantation. Three patients (cases 6, 7, and 8) continued to have regular monthly bleeds during 22 to 36 months. Their initial reason for wanting to discontinue treatment was lack of symptoms, and they decided to restart treatment

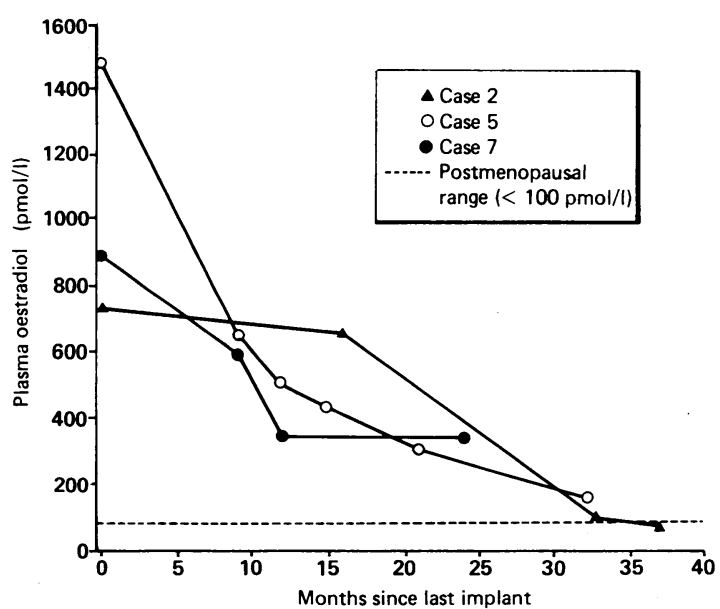

Plasma oestradiol concentrations in three women (table) at time of last implant and during observation period when symptoms eventually returned. Two patients subsequently continued to have withdrawal bleeding 12 and 21 months after the last implantation.

Plasma oestradiol concentration was measured during the observation period in cases 2,5 , and 7 (figure). The oestradiol concentrations at the time of the final implant were within the premenopausal range (less than $1200 \mathrm{pmol} / \mathrm{h}$, the periovulatory mid-cycle peak) in cases 2 and 7, but were supraphysiological in case 5. The postmenopausal range of oestradiol concentrations is shown (less than $100 \mathrm{pmol} / \mathrm{l}$ ).

\section{Discussion}

To our knowledge prolonged endometrial stimulation after serial treatment with oestradiol implants has not been reported previously. We have little doubt that the implants were responsible; we studied typical postmenopausal women with symptoms and at least 12 months of amenorrhoea before treatment with oestradiol implants was started. Thus their endogenous oestrogen production was low initially. None took any form of oestrogen during the observation period, and the mean age at the end of this period was 56 years. The prolonged endometrial stimulation manifest as withdrawal bleeding in all of them is unlikely to have been caused by oestrogen secreting tumours. Furthermore, four women eventually stopped bleeding spontaneously and three restarted treatment because symptoms of oestrogen deficiency returned, presumably as plasma oestradiol concentrations fell.

Clearly, the manufacturers must revise their recommendations about the "duration" of $50 \mathrm{mg}$ implants. The information quoted in the British National Formu$l a r y^{6}$ does not seem to be supported by reliable data and needs revision. The Data Sheet Compendium ${ }^{5}$ seems to be more accurate, and we agree that to achieve relief of symptoms patients may require reimplantation every four to eight months.

The manufacturers must clearly differentiate, however, between the duration of the effect of an implant on relief of symptoms and the duration of its effect on the endometrium. Symptoms may recur when plasma oestradiol concentrations drop to around $320 \mathrm{pmol} / \mathrm{l}$, which occurs about 16 weeks after insertion of a $50 \mathrm{mg}$ implant.' They can also recur at much higher plasma values, in excess of $1500 \mathrm{pmol} / \mathrm{l} .^{7}$ We previously reported pronounced endometrial stimulation in postmenopausal women treated with oestrogen who had plasma oestradiol concentrations of only $180 \mathrm{pmol} / 1,{ }^{89}$ and even lower concentrations may cause proliferation. Thus the plasma oestradiol concentration at which symptoms recur should not be equated to that at which endometrial stimulation stops.

The other important factor, as far as endometrial response is concerned, is the long time after implantation that plasma oestradiol concentrations remain 
raised above the stimulatory threshold. This gradual decline suggests that the implanted oestradiol is eliminated from body tissues much more slowly than thought previously (figure). We emphasise that according to the recommendations in the Data Sheet Compendium our patients were not overdosed but were treated with a conventional regimen of $50 \mathrm{mg}$ oestradiol implants reinserted roughly every six months. The mean oestradiol dose a year was $83 \mathrm{mg}$, which we would not consider to be excessive. Two of the three patients on whom data are available had plasma oestradiol values within the premenopausal range at the time of the last implant.

Our main anxiety with long lasting implants is the long term risk of endometrial malignancy. Less than three years of treatment with oral, unopposed oestrogens increases the risk of endometrial cancer ninefold for two to 14 years after treatment is withdrawn. ${ }^{10} \mathrm{We}$ suspect that prolonged unopposed stimulation by oestrogen after discontinuation of implant treatment will increase the risk of endometrial neoplasia and hence progestogen needs to be added monthly for as long as withdrawal bleeding occurs. Even then endometrial hyperplasia may arise (cases 5 and 9). This could have been due to an inadequate progestogen dose or to poor compliance. Patients with implants who fail to comply strictly with taking progestogen are known to be at an increased risk of endometrial hyperplasia: one series reported an incidence of $56 \%$."

Achieving good compliance with taking progestogen may be difficult. Symptomatic and psychological side effects are well recognised, ${ }^{+}$and there can be few women who perceive a monthly withdrawal bleed as a blessing. Implant treatment in women with an intact uterus carries the possibility of a long term commitment to taking progestogen; clinicians should advise their patients to continue taking progestogen cyclically for as long as the withdrawal bleeding continues, not for a defined period of time such as four to eight months after the last implantation.

We thank the Imperial Cancer Research Fund Laboratories, London WC2, for the financial help given to MIW.

1 Thom MH, Collins WP, Studd JWW. Hormone profiles in postmenopausal women after therapy with subcutaneous implants. Br $\mathcal{F}$ Obstet Gynaecol 1981;88:426-33.

2 Savvas M, Studd JWw, Fogelman I, Doolev M, Montgomery J, Murby B. Skeletal effects of oral oestrogen compared with subcutaneous oestrogen and testosterone in postmenopausal women. Br Med f 1988;297:331-3.

3 Persson I, Adami H-O, Bergkvist L, et al. Risk of endometrial cancer after treatment with oestrogens alone or in conjunction with progestogens: results of a prospective study. Br Med f 1989;298:147-51.

4 Magos AL, Brewster E, Singh R, O'Dowd T, Brincat M, Studd JWw. The effects of norethisterone in postmenopausal women on oestrogen replacement therapy: a model for the premenstrual syndrome. Br f Obstet Gynaecol 1986;93:1290-6

Anonymous. Data sheet compendium. London: Datapharm Publications, $1989-90: 1143$

6 British Medical Association and the Royal Pharmaceutical Society of Great Britain. British national formulary. Number 17. London: Pharmaceutical Press, 1989:254.

7 Gangar K, Cust M, Whitehead MI. Symptoms of oestrogen deficiency associated with supraphysiological plasma oestradiol concentrations in women with oestradiol implants. Br.Med f 1989;299:601-2.

8 Whitehead MI, Padwick ML, Endacott J, Pryse-Davies J. Endometrial responses to transdermal estradiol in postmenopausal women. Am $\mathcal{F}$ Obstet responses to transdermal est

9 Padwick ML, Endacott J, Whitehead MI. Efficacy, acceptability, and metabolic effects of transdermal estradiol in the management of postmen pausal women. Am F Obstet Gynecol 1985;152:1085-91.

10 Paganini-Hill A, Ross RK, Henderson BE. Endometrial cancer and patterns of use of oestrogen replacement therapy: a cohort study. $\mathrm{Br} \mathcal{F}$ Cancer 1989;59:445-7.

1 Paterson MEL, Wade-Evans T, Sturdee DW, et al. Endometrial disease after treatment with oestrogens and progestogens in the climacteric. $\mathrm{Br} \mathrm{Med} \mathcal{f}$ $1980 ; 280: 822-4$

(Accepted 13 December 1989

\section{Omeprazole for duodenal ulceration in Crohn's disease}

\section{R M Valori, R Cockel}

Division of Medicine, Selly Oak Hospital, Birmingham B29 6JD

R M Valori, MRCP, senior registrar in medicine R Cockel, FRCP, consultant physician

\section{Correspondence to:}

Dr R M Valori, Queen

Elizabeth Hospital,

Birmingham B15 2TH.

BrMed f 1990;300:438-9
Antroduodenal ulceration associated with Crohn's disease is fairly unresponsive to medical treatment and often leads to pyloric or duodenal obstruction that requires surgery. ${ }^{\prime}$ We describe two cases of duodenal ulceration in Crohn's disease that were unresponsive to conventional antiulcer treatment but healed when treated with omeprazole.

\section{Case reports}

Case 1-A 39 year old white woman with a 17 year history of duodenal ulceration had a right hemicolectomy for terminal ileal Crohn's disease but continued to complain of constant upper abdominal pain. Radiology showed duodenal ulceration and a recurrence of Crohn's disease in the neoterminal ileum. A reducing course of prednisolone had no effect, and her pain was not completely relieved by cimetidine (up to $2400 \mathrm{mg}$ /day), antacids, alginates, or sucralfate. She could not tolerate bismuth chelate. Endoscopy two years after the operation disclosed two active duodenal ulcers. Duodenal biopsy showed only chronic inflammatory changes. Her serum gastrin concentration was $49 \mathrm{ng} / \mathrm{l}$ (normal range $<100 \mathrm{ng} / \mathrm{l}$ ). Omeprazole $40 \mathrm{mg} /$ day completely relieved the pain within 14 days, and the ulcers had healed when endoscopy was performed four weeks later. The ulceration returned when omeprazole was stopped, although she continued to take high doses of cimetidine. Her symptoms were subsequently controlled with two month courses of omeprazole $20 \mathrm{mg} /$ day and cimetidine $1200 \mathrm{mg} /$ day alternately.

Case 2-A 30 year old white man who had had a right hemicolectomy for terminal ileal Crohn's disease at age 22 and resection of the anastomosis for recurrence with obstructive symptoms six years later developed epigastric pain. Endoscopy showed a large duodenal ulcer. Various combinations of steroids, sucralfate, antacids, bismuth chelate, and high doses of ranitidine (up to $600 \mathrm{mg} /$ day) provided incomplete relief of his symptoms. Three endoscopies performed over the next two years showed continuing ulceration and almost complete obstruction of the duodenum. Duodenal biopsy showed chronic inflammation. He was admitted to this hospital with severe pain and vomiting while being treated with ranitidine and sucralfate. Examination showed abdominal tenderness and a succussion splash. Another endoscopy confirmed ulceration with distortion and oedema of the duodenal cap. Omeprazole $40 \mathrm{mg} /$ day completely relieved the symptoms in 10 days. Endoscopy after four weeks of treatment showed a small duodenal ulcer; four weeks later the duodenum looked normal. He subsequently had occasional dyspeptic symptoms, which were controlled with antacids and infrequent courses of ranitidine.

\section{Comment}

Ulceration of the duodenal cap in patients with Crohn's disease may be peptic in origin or due to the Crohn's disease. Differentiation of the two causes by mucosal biopsy is unreliable.' Fielding and Cooke reported that peptic ulceration occurs more commonly in patients with ileal Crohn's disease than in the general population. ${ }^{2}$ Pathological data were, however, lacking and the findings were incidental in a group of patients investigated for small bowel symptoms. Duodenal 